\title{
GIS-based Calibration of MassMov2D
}

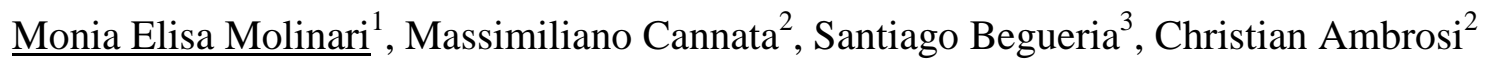

${ }^{1}$ Department of Earth and Environmental Sciences, University of Pavia, Pavia, Italy

${ }^{2}$ Institute of Earth sciences, University of Applied Sciences and Arts of Southern Switzerland, Canobbio, Switzerland

${ }^{3}$ Estación Experimental de Aula Dei, Consejo Superior de Investigaciones Científicas (EEADCSIC), Zaragoza, Spain

Running head: GIS-based Calibration of MassMov2D

Keywords: environmental modeling, Geographic Information System (GIS)

Corresponding author: Monia Elisa Molinari, Department of Earth and Environmental Sciences, University of Pavia, Via Ferrata 1, Pavia, Italy, moniaelisa.molinari01@ ateneopv.it 


\begin{abstract}
MassMov2D is a numerical model for simulating runout and deposition of landslide phenomena over a complex topography that is implemented in the free GIS PCRaster. This research aims at improving the mechanism of MassMov2D calibration and verifying its capability of representing complex landslides. In this paper the authors present the enhancement of the MassMov2D code due to the introduction of the Nash-Sutcliffe coefficient for model efficiency calculation; this enables the replacement of the inefficient 'trial and error' approach used for sensitivity analysis and calibration with a semiautomatic procedure. During this research the improved code was tested in a case study located on the Canaria Valley (Switzerland) where a complex landslide occurred. An optimal set of parameters were calculated for evaluating the effects of a possible further slope failure.

The availability of a unique dataset of high resolution digital elevation models just before and after the collapse allows to precisely evaluate the sensitivity analysis and calibration of the model with the new procedure. The results demonstrate that this model is capable of reproducing the observed deposits even though some model limitations were identified in steep slope areas. Finally the study presents the expected scenario due to future landslide.
\end{abstract}




\section{Introduction}

The purpose of this study is the simulation of a rapid moving landslide, which is a natural phenomenon that for frequency and severity is certainly one of the most dangerous that may occur in mountainous regions. This event is generally unpredictable due to the high level of complexity of its dynamics; in fact it may involve different types of materials (rock, terrain, debris) and evolve in multiple types of movement mechanisms (sliding, falling, earth flow, complex falls, rock avalanche).

Currently the modeling of this phenomenon is an important research field because a detailed analysis of the runout can provide estimates on the expected impact area and the probable distribution of deposits. This information is a useful insight for the development of risk mitigation strategies.

In literature both empirical and physically-based models exist. Empirical models estimate, on the basis of historical data analyses, the correlations among different characteristics of the landslide; for example the detached volume and the reach angle in Corominas (1996) or the area of deposits and volume in Iverson et al. (1998). This type of approach allows to predict runout distances or deposits extension but, according to Hungr (2006), it "suffers from great scatter of data, making even the limited predictions very unreliable".

In the last years, scientists have concentrated their efforts in developing physically-based models that are capable of providing a more realistic and, thanks to the usage of physically-based parameters, a more meaningful description. Within these models, the dynamic approach seems to have the potential to be the most accurate, objective, and accessible method for the analysis of landslides with rapid dynamics (McDougall 2006). It applies mass, momentum and energy conservation equations for the description of the terrain movements together with rheological formulas (Bingham, Voellmy, frictional, etc.) able to characterize the type of material.

Hungr (1995) gave a great contribution in this research field with the development of DAN-W, which is a bidimensional model based on the Lagrangian solution of the motion equations. Afterwards, 
in order to account for complex topographies, the formulation was extended to three dimensions and included in the DAN3D model (McDougall and Hungr 2004). Numerous applications of these two models are described in literature (McKinnon et al. 2008, Sosio et al. 2008, Willenberg et al. 2009). In the recent years, many other dynamic models have been developed: as an example TITAN2D (Pitman et al. 2003), RASH3D (Pirulli 2005) and MassMov2D (Begueria et al. 2009a).

Among these recently developed models, MassMov2D is one of the latest and has the great advantage to be freely available on the Internet (CSIC 2009) with open access to the source code; this allows for easy understanding of the algorithms, and for testing and improving of the original code. This model, based on an Eulerian approach, is able to provide a three-dimensional description of the mass movements over digital terrain models; its applications account for both debris-flows and rock avalanches modeling (Begueria et al. 2009b).

The goals of this research are to: a) test the MassMov2D capability to correctly simulate a complex landslide collapse, b) improve the model calibration process by integrating in the code a semiautomatic procedure, c) derive an optimal set of parameters values to be applied in other similar conditions, and d) evaluate the intensity map of a collapsing scenario for future risk assessment. With this propose the Val Canaria (Ticino, Switzerland) case has been studied.

In the next paragraphs, the authors illustrate the model characteristics, the case study framework, the improved sensibility analysis and calibration, the evaluated possible risk scenario, and the conclusions.

\section{MassMov2D Model}

\subsection{Governing equations}

MassMov2D is a numerical model that allows to simulate the expansion (runout) and deposition of mass movements over a complex topography by approximating the heterogeneous sliding mass to a homogeneous one-phase fluid (following the approach proposed by Savage and Hutter 1989, Iverson and Denlinger 2001). 
The model describes the mass movements as a two-dimensional flux taking advantage of the shallow water equations. This formula is derived from the general Navier-Stokes equations under the hypothesis that the vertical components of velocity and pressure are negligible with respect to the horizontal components, and that the vertical pressure profile can be considered as almost hydrostatic (Kinnmark 1985).

These assumptions allow for the integration of the equations along the vertical component $z$ deriving a $2 \mathrm{D}$ description of the flux that avoids the complex 3D representation. The shallow water equations that drive the model, represented in a 2D Euclidean space with Cartesian coordinates $x, y$ (see Figure 1), are:

$$
\begin{aligned}
& \frac{\partial u}{\partial t}+\cos \alpha_{x} u \frac{\partial u}{\partial x}+\cos \alpha_{y} v \frac{\partial u}{\partial y}=-\cos \alpha_{x} g\left(\operatorname{tg} \alpha_{x}+k \frac{\partial\left(\cos \alpha_{x} h\right)}{\partial x}+\left(\frac{-u}{\sqrt{u^{2}+v^{2}}} S_{f}\right)\right) \\
& \frac{\partial v}{\partial t}+\cos \alpha_{y} v \frac{\partial v}{\partial x}+\cos \alpha_{x} u \frac{\partial v}{\partial y}=-\cos \alpha_{y} g\left(\operatorname{tg} \alpha_{y}+k \frac{\partial\left(\cos \alpha_{y} h\right)}{\partial y}+\left(\frac{-v}{\sqrt{u^{2}+v^{2}}} S_{f}\right)\right) \\
& \frac{\partial h}{\partial t}+\cos \alpha_{x} \frac{\partial(h u)}{\partial x}+\cos \alpha_{y} \frac{\partial(h v)}{\partial y}=0
\end{aligned}
$$

Where: $t$ is the time [s]; $h$ is the flux depth along the normal [m]; $u$ and $v$ are the $x$ and $y$ components of the velocity vector $[\mathrm{m} / \mathrm{s}] ; \alpha_{x}$ and $\alpha_{y}$ are the angles between the sliding surface and the horizontal plane in the direction $x$ and $y[\mathrm{deg}] ; g$ is the gravity acceleration $\left[\mathrm{m} / \mathrm{s}^{2}\right] ; S_{f}$ is a parameter accounting for the energy dissipation [-] as a function of the rheological properties of the flux, here considered homogeneous and constants; and $k$ is the earth pressure coefficient [-]: the ratio between the tangential and normal stresses. $k$ ranges between two extreme values, $K_{p}$ and $K_{a}$, which correspond, respectively, to the passive and active state of the Rankine theory (Rankine 1857) and are calculated as a function of the angle of internal friction $\delta$ as follows:

$$
K_{a}=\frac{1-\sin \delta}{1+\sin \delta}
$$




$$
K_{p}=\frac{1+\sin \delta}{1-\sin \delta}
$$

Equations (1) and (2) express, in terms of accelerations, the momentum balance along the horizontal directions. In the numerical solution they are applied to estimate the evolution in time of flux velocities $u$ and $v$ as a function of the convective acceleration due to the movement, and of the local acceleration due to the combination of three forces: gravity, pore pressure and flux resistance.

Equation (3) expresses the mass balance and, once that the flux velocities are known, allows to evaluate the variation in time of the deposit depth $h$.

FIG1

\subsection{Rheological equations}

In Equations (1) and (2), the term $S_{f}$ accounts for the flux resistance as a function of the rheology and drives the mass expansion. MassMov2D permits to select one of the following rheological laws:

- frictional - based on the frictional basal angle $\varphi$ only;

- Voellmy (1955) - here the frictional component is added to a turbulent component dependent on a turbulence factor $\xi$, the square of velocity $U$ and the flux depth $h$;

- Bingham (Coussot 1997) - visco-plastic model that describes the flux behavior as a function of: density $\rho$, dynamic viscosity $\mu$ and constant yield stress $\tau_{c}$ due to cohesion;

- Coulomb (Begueria et al. 2009a) - viscous model that replaces the cohesive term of the Bingham law with a cohesion-friction combination term, making it dependent not only on the constant yield stress $\tau_{c}$ but also on the basal frictional angle $\varphi$.

Depending on the selected rheology law, the $S_{f}$ term of Equations (1) and (2) has the following formulation:

frictional: $\quad S_{\mathrm{f}}=\tan \varphi$

Voellmy: $\quad S_{f}=\tan \varphi+\frac{U^{2}}{h \xi}$ 


$$
\begin{array}{ll}
\text { Bingham: } & S_{f}=\frac{1}{h \rho}\left(\frac{3}{2} \tau_{c}+\frac{3 \mu}{h} U\right) \\
\text { Coulomb: } & S_{f}=\tan \varphi+\frac{1}{h \rho}\left(\frac{3}{2} \tau_{c}+\frac{3 \mu}{h} U\right)
\end{array}
$$

\subsection{Input and output parameters}

The MassMov2D code is distributed under an 'Attribution Non-Commercial Share Alike' license and is implemented within PCRaster (Wesseling et al. 1996, Karssenberg et al. 2001), a free software developed by the geosciences faculty of Utrecht university.

The model requires a series of raster maps describing the morphology like the sliding surface topography (digital terrain model without the sliding body), the initial sliding mass thickness and the 'distance map' representing the cells distance from the landslide toe. Other input parameters that characterize the mass material are: density $\left[\mathrm{kg} / \mathrm{m}^{3}\right]$, apparent yield stress $[\mathrm{Pa}]$, Chèzy roughness coefficient $\left[\mathrm{m} / \mathrm{s}^{2}\right]$, dynamic viscosity $[\mathrm{Pa} \bullet \mathrm{s}]$, basal friction angle [deg], internal friction angle of the sliding mass during the expansion $[\mathrm{deg}]$, and the fluid rate $[\mathrm{m} / \mathrm{s}]$. This last parameter provides information on the transaction velocity of the sliding mass when passes from a solid state to a fluid state; together with the 'distance map' it allows to define the amount of mass mobilized as a function of time. It is worth noting that depending on the selected rheological law different sets of parameters are mandatory. In addition the module requires the maximum time step number or the spatial computational domain to set the simulation.

The main outputs of the model are two time series raster representing flux velocity and deposit depth; optionally additional reports about other variables like volumes or flux forces can be produced.

\section{Case Study}

\subsection{The Cè complex landslide}

The Canaria valley is the case study area. It is located in Northern Ticino (Switzerland) close to the San Gottardo Alps corridor where critical infrastructures for road and train connections between 
Central and South Europe are located.

The Canaria valley, with the exception of the Airolo and Madrano villages, has historically few permanent residents but accounts for numerous visitors and touristic cottages. At its bottom the Canaria river flows into the Ticino river a few meters away from the highway and the railway.

From a geological point of view the valley is characterized by two major tectonic units: the Penninic nappes on the South, and the Gotthard crystalline massif and Mesozoic sediments, being part of the Helvetic domain, on the North. In particular, the area object of this study is characterized by the presence of dolomites, anhydrites, and gypsum being part of the Gotthard Mesozoic sedimentary cover, interested by folds and faults with a sub-vertical axis that create a very complex tectonic structure. Due to this particular geological setting, the entire region is affected by numerous types of gravitative phenomena that have produced heavy damages to vacation cottages in the last years. The most dangerous instability is the complex landslide in the Cè area, located on the left side of the valley and characterized by the presence of anhydrites; due to hydration caused by water infiltration they turned into gypsum with an increment of the volume up to $60 \%$ that generated rock fractures followed by karstifications and weathering. All these processes are responsible of the general reduction of the rock mass properties and consequent instability phenomena.

Of particular interest are the events which occurred in 2007, 2009 and 2010. In 2007 a mass of about $40,000 \mathrm{~m}^{3}$ fell from the central part of the landslide crown, and the deposits arrived close to the river without any consequences. In October 2009, a collapse of the central and left side of the landslide crown (see Figure 2) involved about $350,000 \mathrm{~m}^{3}$, and in this case the deposits reached the valley bottom and destroyed the nearby road. Fortunately, the granulometry of the deposit was coarse (mass blocks up to $1,000 \mathrm{~m}^{3}$ ) and the river flow was not significantly interrupted at that time.

FIG2

In the summer 2010, due to intense rainfalls, the deposits of the 2009 event together with the debris 
transported by the river generated a temporary natural dam that collapsed. The consequent flood wave eroded the river bank causing the destruction of a large part of the road (meanwhile rebuilt) and washed away two rural houses. The generated debris flow did not reach the end of the valley.

\subsection{Data}

Due to the existing risk situation, the Canaria valley has been monitored for a long time with regular measurements of hydrometry, groundwater level, snow depth, rainfall, and superficial displacements (by periodic GPS and total station campaigns). Moreover, besides the traditional monitoring, the Cè slope is yearly surveyed with terrestrial LiDAR (Light Detection And Ranging), a technique that allows for dense measuring of surfaces by means of 3 dimensional point clouds. From this type of measures it is possible to derive accurate digital surface terrain models capturing the topography of the landslide and of its deposits at a given time.

Regarding the 2009 event, a periodic geodetic survey conducted 10 days before the failure measured an increase of displacements of monitoring points all over the valley; in particular in the Cè area, displacements were calculated to range between 3 and $9 \mathrm{~cm} .12$ days after the event, a specific survey in the Cè area observed additional displacement of the upward part of the slide quantified in $2-3 \mathrm{~cm}$ (about $0.2-0.3 \mathrm{~cm} /$ day).

Additional important observations were derived from LiDAR campaigns. In fact, by chance two LiDAR surveys of the landslide area were conducted the day before (26 October 2009) and a few days after (30 October 2009) the collapse. These two measurements were particularly crucial in the analysis of the event. In fact, we could derive pre and post-event digital terrain models (DTM) at 1 m resolution by integrating terrestrial laser scanning data with the surrounding available airborne LiDAR points cloud by means of bilinear splines interpolation (Brovelli et al. 2004).

Afterwards, the depths and shape of the deposit and the initial landslide body were identified with high precision by comparing the two terrain models, which is invaluable information for the correct 
calibration of MassMov2D. The volumetric analysis recognized a collapsing volume of 353,000 $\mathrm{m}^{3}$ and a deposit volume of $512,000 \mathrm{~m}^{3}$, and this corresponds to a volume expansion of $45 \%$.

The generation of the model input maps was performed by taking advantage of several GRASS GIS modules (GRASS Development Team, 2011), in particular: a) the sliding surface was calculated by subtracting the collapsing body from the pre-event DTM (r.mapcalc), b) the collapsing body thickness was evaluated by considering the negative differences between the post and pre-event DTM multiplied for the cosine of the slope (r.mapcalc and r.slope.aspect), c) the distance map from the landslide toe was obtained by applying the r.grow.distance module to the rasterized limits of the landslide, and d) the computational domain map was derived by setting the value of 1 on the bounding box limits and 0 elsewhere so that the open boundary condition were applied (r.mapcalc).

MassMov2D does not account for volume expansion caused by the increment of void volumes. This means that a model result and the ground truthing cannot be directly compared; for this reason, the deposit thickness (calculated with the same procedure adopted for the collapsing body thickness) was reduced by a factor of $0.689\left(353,000 \mathrm{~m}^{3} / 512,000 \mathrm{~m}^{3}\right)$. In Figure 3 the deposit and the collapsing body thickness are mapped.

FIG3

\section{Improved Sensitivity Analysis and Calibration of MassMov2D}

In order to determine the values of the MassMov2D parameters that allow for the simulation of future events, of the same type and characterized by the same materials properties, the authors conducted a sensitivity analysis (Morgan and Henrion 1990) to individuate the parameters that have a significant influence on the model results and a model calibration (Hill 1998) to find values of model input parameters able to guarantee the optimal correspondence between observed and simulated data.

To accomplish this task it is very important to focus the attention on the landslide deposits trying to simulate its values (extension and thickness) as accurately as possible; for this reason the efficiency 
coefficient $N$ described in Nash and Sutcliffe (1970) has been integrated into the model code.

In relation to the deposit thickness, the Nash-Sutcliffe coefficient $N$ is formulated as follows:

$$
N=1-\frac{\sum_{x}\left(H_{\mathbf{o}}^{\mathbf{x}}-H_{\mathbf{m}}^{\mathbf{x}}\right)^{2}}{\sum_{x}\left(H_{\mathbf{o}}^{\mathbf{x}}-\bar{H}_{o}\right)^{2}}
$$

Where $H_{o}^{x}$ is the observed deposit thickness at the $x$ cell, $H_{m}^{x}$ is the simulated deposit thickness at the $x$ cell and $\bar{H}_{o}$ is the average observed deposit thickness.

The Nash-Sutcliffe coefficient $N$ provides a measure of the simulation goodness-of-fit (from a quantitative and spatial point of view) with respect to the observations. It is defined between 1 and $-\infty$ : when $N=1$ simulation and observed values are exactly the same either in terms of magnitude and space, when $N=0$ the model simulations are as accurate as the average of the observations, finally when $\mathrm{N}<0$ the average of the observations is more accurate than the simulations.

Moreover, Nash-Sutcliffe coefficient is also used to estimate the time at which a simulation can be considered concluded: $N$ is evaluated at each time step and if its value does not significantly vary (difference less than 0.0001) in three consecutive steps the simulation is closed.

Taking advantage of this model enhancement the user can provide an observed deposit thickness (eventually reduced to remove the volume expansion) as a new model input and obtain the final simulation Nash-Sutcliffe coefficient value.

\subsection{Sensitivity analysis}

The sensitivity analysis is based on a predefined range of parameters values; in Table 1 the selected ranges are reported. For the case study the authors selected the Voellmy rheological law that has been already successfully applied for the simulation of debris flows and rock avalanches (Hungr and Evans 1996). The chosen limits of the basal friction and Chèzy (parameters that define the Voellmy rheological law) were derived from literature (Hungr and Evans 1996, Hungr et al. 2007, Sosio et al. 2008). The ranges of internal friction angle and the fluidization rate were driven by physically 
meaningful limits due to missing literature reference values. Other rheological parameters have not been evaluated because they are not used by the applied Voellmy rheology.

\section{TABLE1}

The sensitivity analysis was performed in four different simulations sets, and in each one a single parameter was varied while others took the medium value of the defined variation range. The results of the simulations sets are graphed in Figure 4 where the variation of Nash-Sutcliffe coefficient as a function of the variation of the parameters values is represented.

\section{FIG4}

Figure 4 highlights the high sensitivity of the model to changes of basal friction values; Chèzy and internal friction coefficients also influence the model output, although in a less significant way. The fluid rate parameter does not affect the model output variation (negligible effect). While the curve related to the basal friction is parabolic with a single maximum value, others curves are characterized by irregular behavior. Irregularities in the relationship between $N$ and these parameters can probably be associated with numerical instability of the model which affects more the internal friction and Chèzy coefficients because their effect on the flow depends, respectively, on the velocity and the velocity squared. Based on these considerations, basal friction, Chèzy and internal friction coefficients were accounted in the calibration process, while the fluid rate parameter was excluded and set to a constant value of $10 \mathrm{~m} / \mathrm{s}$.

\subsection{Model calibration}

The calibration process consists of searching for the optimal parameter combination that produces model simulations capable of representing as close as possible the observed reality. With respect to the sensitivity analysis, in this process all the possible combinations of parameters values within predefined ranges are evaluated by means of Nash-Sutcliffe coefficient $N$.

The work was conducted in two consecutive phases (see Table 2). The first was a coarse calibration 
that was characterized by high variation and large ranges of parameters values. This phase allowed to obtain a finer sets of intervals of optimal values identified by simulations with $N$ bigger than 0.6 . The second phase was a fine calibration performed within the ranges derived by the coarse calibration and with smaller parameters values variations. This phase led to the identification of optimal parameters sets.

\section{TABLE2}

The overall results displayed two optimal sets of parameters values, both characterized by NashSutcliffe values of about 0.67 . This may be due to the difficulty in modeling values of Chèzy and internal friction coefficients which, as previously stated, are influenced by the velocity; in this case, having no information about the velocity of the flow during the event, it was not possible to restrict further the range of these two parameters.

The values of the two optimal sets are reported in Table 3.

\section{TABLE3}

Compared to set 1, the set 2 presents higher values of Chèzy coefficient and basal friction angle. These two parameters have an opposite effect on the final deposit simulation (see Equation (7)); in fact a higher basal friction angle produces slower flow and thus more deposition close to the landslide crown, on the opposite a higher Chèzy value produces a faster flow (and hence momentum) and thus major deposition at the landslide toe.

These considerations are confirmed by the analysis of the deposition obtained with the two sets of parameters (simulation 1 applying parameter set 1 and simulation 2 applying set 2). The difference map (Figure 5) shows negligible values, with an absolute average of about $0.3 \mathrm{~m}$ and a standard deviation of about $0.6 \mathrm{~m}$. The image illustrates deposit depths slightly higher for the simulation 1 at the bottom of the accumulation area (positive values) and lower values in the middle part (negative values). The high values at the border of the map are due to differences in the extension of the deposit area. Among the 
two optimal sets, we selected the set 2 because higher value of the internal friction angle seems to better represent the physical characteristics of the mass.

\section{FIG5}

Figure 6 shows the differences between the deposit thickness map derived from pre and post-event DTM (herein after referred to as OD) and the one generated by the model. The histogram shows discrepancies varying between $-11 \mathrm{~m}$ and $+11 \mathrm{~m}$, with an absolute average of $3 \mathrm{~m}$ and a standard deviation of $4.1 \mathrm{~m}$.

At the top of the landslide (area 1 of Figure 6) we found negative differences, which can be due to limitations in the methodology used to derive OD. In fact, the difference between the pre and the postevent maps does not provide information about deposit thickness in the initial landslide area. Still, we know that actually there was deposition in this area (see Figure 2), but we cannot perform additional field measurements in the upper part of the landslide because of the existing risk situation.

The central part of the landslide (area 2 of Figure 6) is the most critical area; here the model underestimates the deposition. We can suppose that this problem in the simulation arises because of the steepness of the terrain.

The northern part of the deposition (area 3 of the Figure 6) cannot actually be evaluated because in that area the laser scanning data were not available due to the presence of obstructions during the surveys. Here the post-event DTM has been interpolated and thus cannot be considered representative of the real terrain morphology.

The remaining parts of the simulated deposit in correspondence of the river are almost in perfect agreement with the reality; here the differences are very limited and the maximum deposit depth observed $(21.8 \mathrm{~m})$ is well reproduced by the model $(20.4 \mathrm{~m})$.

FIG6

Figure 7 shows a comparison of the two deposit depth profiles illustrated in Figure 6. The A-A' 
transect underlines the difficulties of the model in reproducing observed data in the central part of the landslide; here in correspondence of high slopes the model seems not to be able to arrest the material. Nevertheless, close to the river, the accuracy of the model increase drastically. The transect B-B' confirms the good accuracy of the simulation in this area.

\section{FIG7}

It is worth noting that the capability of the model to accurately reproduce the bottom valley deposit is really important. In fact, in case of risk due to temporary dam breaks, it is essential to correctly identify the shape and the height of the natural dam; this allows for correctly estimates water volumes and flash flood or debris flow runout.

\section{Risk Scenario}

The 2010 event is a clear example of the expected threatening scenario; the recent reactivation of the movements, identified by numerous field inspections, could lead to new landslides. Those, adding further deposits, are likely to increase the intensity of eventual debris flow that in this case might reach the houses of Airolo and the transportation infrastructures of the North-South route. According to geological surveys and field evidences there is the risk of a future new collapse of the right side of the landslide crown. Geological and structural analysis carried out on the 2009 rockfall event together with recent geo-morphological surveys were used to map the probable area of instability (Figure 8), characterized by a mass of about $275,000 \mathrm{~m}^{3}$ and an average thickness of $33 \mathrm{~m}$.

Under the hypothesis that the expected terrain failure generates a landslide of the same material and mechanism of the 2009 event, we can assume that the optimal parameter set individuated with the calibration can be used to predict the expected deposit. Simulation results are proposed in Figure 9. It should be noted that the deposit thickness values obtained from the model have been corrected for volume expansion with the coefficient of volume variation mentioned in the previous paragraph; the same value used in the calibration process was applied. 
The simulation forecasts a deposit that affects both the street and the stream in a very narrow valley point. Taking advantage of the r.watershed GRASS module it was possible to identify the river path in correspondence of the accumulation. The $\mathrm{CC}^{\prime}$ transect (Figure 9) shows that the deposit interests the river bed for about 250 meters reaching values of maximum thickness of 32 meters.

\section{FIG8}

FIG9

\section{Motivation for Porting MassMov2D to GRASS GIS}

Currently the porting of the MassMov2D code to the GIS GRASS is being executed. With the exception of a few routines written in $\mathrm{C}$ language, the original code is based on the scripting language of PCRaster; if this approach has the advantage to easier understanding and access to the code by scientists, it has the disadvantage to slow down the computational time, due numerous system calls and disk writing and reading. Moreover, with the porting of the code to GRASS, MassMov2D will move from the current 'Attribution Non-Commercial Share Alike' to the General Public License (GPL) that will guarantee the right of access, modify, redistribute and use the code. This will permit to access all the primitive functions for their modification, fact that is not currently guarantee by PCRaster which is free but partially proprietary software with closed source core. Furthermore, the GPL will authorize the development of ad-hoc graphical user interfaces to support user friendly usage of the code that is currently forbidden by PCRaster. Finally, the users will have the right to run the software also in commercial projects.

\section{Conclusion and Further Research}

This research has improved the MassMov2D model by implementing a new feature that simplifies and optimizes the sensitivity analysis and calibration within a GIS. In fact, the Nash-Sutcliffe coefficient allows for evaluating the goodness-of-fit of the simulation with respect to the observation surface either from a spatial and quantitative point of view. The application of the modified version of 
the model in a case study allowed us to understand the model parameters and to obtain an optimal set of values capable to reproduce the observed event. The availability of high resolution surfaces of the area before and after the collapse enables the effective evaluation of the model goodness in simulating complex landslides in a unique way, in fact such kind of precise data is very seldom available.

The results of our analysis demonstrate that the model is capable to reproduce the deposits in correspondence of the valley bottom which in the case study is the most important area in terms of expected risk scenario evaluation. Nevertheless, some non-negligible differences with the observations have been identified in the presence of high slopes. In the opinion of the authors, this deficiency is partially because there were no information on the dynamic of the event (evolution in time of the runout) to better calibrate the model, and partially because of the assumptions of the model, that describes the mass movement as a flux. Another important factor that may contribute to this deficiency is the volume expansion that occurs during mass movement; this fact has been currently accounted during the calibration applying a constant reduction factor on the observations and during the simulation applying a constant expansion factor to the calculated deposit. A better modeling of this phenomenon could lead to better calibration and therefore to better simulations. For this reason the authors plan to conduct future research on this topic.

The simulation run with the expected risk scenario showed that a deposit thickness slightly higher than $30 \mathrm{~m}$ could affect the river bed. This suggests that an important flash flood may occur and therefore a detailed simulation of debris-flow downstream is required for assessing the risk of transport infrastructure damage. This investigation is now being performed and will be estimated by means of the r.damflood module developed in GRASS by Cannata and Marzocchi (2012).

As a final remark, we can conclude that the open access to the source code was a prerequisite to modify and enhance the model. The Free and Open Source Software gives the opportunity of generating open research where a wide public of researchers may collaboratively participate at different 
levels. As an effect, after the code porting and license migration, the model will have more chance to be tested and improved by scientists.

\section{Acknowledgments}

This research was conducted under the Interreg IIIA project MIARIA (Adaptive Hydrogeological Monitoring supporting the Area Integrated Risk Plan). This project, focused on the Alpine environments, aims at developing innovative technologies for landslide monitoring and at evaluating dynamic risk scenarios taking advantage of the numerical modeling. The authors thank Jeff McKenna from Gateway Geomatics for his support in language correction of this paper. 


\section{References}

Begueria S, Van Asch ThWJ, Malet JP, and Gröndhal S 2009a A GIS-based numerical model for simulating the kinematics of mud and debris flows over complex terrain. Natural Hazards and Earth System Sciences 9: 1897-1909

Begueria S, Van Hees MJ, and Geertsema M 2009b Comparison of three landslide runout models on the Turnoff Creek rock avalanche, British Columbia. In Malet JP, Remaître A, and Bogaard T (eds) Landslide Processes: From Geomorphology Mapping to Dynamic Modelling. Strasbourg, CERG Editions: $243-47$

Brovelli MA, Cannata M, and Longoni UM 2004 LIDAR data filtering and DTM interpolation within GRASS. Transactions in GIS 8: 155-74

Cannata M and Marzocchi R 2012 Two-dimensional dam break flooding simulation: a GIS embedded approach. Natural Hazard 60: in press

Corominas J 1996 The angle of reach as a mobility index for small and large landslides. Canadian Geotechnical Journal 33: 260-71

Coussot P 1997 Mudflow Rheology and Dynamics. Rotterdam, IAHR /AA Balkema

CSIC 2009 Consejo Superior de Investigaciones Científicas. WWW document, http://digital.csic.es/handle/10261/11804

GRASS Development Team 2011 Geographic Resources Analysis Support System (GRASS) Software. WWW document, http://grass.osgeo.org

Hill MC 1998 Methods and Guidelines for Effective Model Calibration.Washington, D.C., U.S. Geological Survey, Water Resources Investigations Report No 98-4005

Hungr O 1995 A model for the runout analysis of rapid flow slides, debris flows and avalanches. Canadian Geotechnical Journal 32: 610-23

Hungr O 2006 Prospects for prediction of landslide dam geometry using empirical and dynamic 
models. Italian Journal of Engineering Geology and Environment, special issue 1: 151-55

Hungr O and Evans SG 1996 Rock avalanche runout prediction using a dynamic model. In Senneset K (ed) Proceedings of the Seventh International Symposium on Landslides. Rotterdam, AA Balkema, $1: 233-38$

Hungr O, Morgenstern NR, and Wong HN 2007 Review of benchmarking exercise on landslide debris runout and mobility modelling. In Ho K and Li V (eds) Proceedings of the International Forum on Landslide Disaster Management. Hong Kong, The Hong Kong Institution of Engineers 2: 755-812 Iverson RM and Denlinger RP 2001 Flow of variably fluidized granular masses across threedimensional terrain: 1, Coulomb mixture theory. Journal of Geophysical Research 106: 537-52 Iverson RM, Schilling SP, and Vallance JW 1998 Objective delineation of lahar inundation hazard zones. Geological Society of America Bulletin 110: 972-84

Karssenberg D, Burrough PA, Sluiter R, and De Jong K 2001 The PCRaster Software and Course Materials for Teaching Numerical Modelling in the Environmental Sciences. Transactions in GIS 5(2): 99-110

Kinnmark IPE 1985 The shallow water equations: formulation, analysis and application. In Brebia CA and Orszag SA (eds) Lecture Notes in Engineering 15.Berlin, Springer-Verlag: 1-187

McDougall S 2006 A new continuum dynamic model for the analysis of extremely rapid landslide motion across complex 3D terrain. Unpublished Ph.D. Dissertation, University of British Columbia McDougall S and Hungr O 2004 A model for the analysis of rapid landslide motion across threedimensional terrain. Canadian Geotechnical Journal 41: 1084-97

McKinnon M, Hungr O, and McDougall S 2008 Dynamic analyses of Canadian landslides. In Locat J, Perret D, Turmel D, Demurs D, and Leroueil S (eds) Proceedings of the Fourth Canadian Conference on GeoHazards: From Causes to Management. Laval, QC, Presse de l'Université de Laval: 203-09 
Morgan MG and Henrion M 1990 Uncertainty: A Guide to Dealing With Uncertainty in Quantitative Risk and Policy Analysis. New York, Cambridge University Press

Nash JE and Sutcliffe JV 1970 River flow forecasting through conceptual models: Part I, A discussion of principles. Journal of Hydrology 10: 282-90

Pirulli M 2005 Numerical modelling of landslide runout, a continuum mechanics approach. Unpublished Ph.D. Dissertation, Politecnico di Torino

Pitman EB, Nichita CC, Patra AK, Bauer AC, Sheridan M, and Bursik M 2003 Computing granular avalanches and landslides. Physics of Fluids 15: 3638-46

Rankine W 1857 On the stability of loose earth. Philosophical Transactions of the Royal Society of London 147: 9-27

Savage SB and Hutter K 1989 The motion of a finite mass of granular material down a rough incline. Journal of Fluid Mechanics 199: 177-215

Sosio R, Crosta GB, and Hungr O 2008 Complete dynamic modeling calibration for the Thurwieser rock avalanche (Italian Central Alps). Engineering Geology 100: 11-26

Voellmy A 1955 Über die Zerstörungskraft von lawinen. Schwerizerische Bauzeitung 73: 159-65, $212-$ $17,246-49,280-85$

Wesseling CG, Karssenberg D, Van Deursen W, and Burrough PA 1996 Integrating dynamic environmental models in GIS: the development of a Dynamic Modelling language. Transactions in GIS 1: 40-48

Willenberg H, Eberhardt E, Loew S, McDougall S, and Hungr O 2009 Hazard assessment and runout analysis for an unstable rock slope above an industrial site in the Rivera valley, Switzerland.

Landslides 6: 111-19 


\section{Tables}

Table 1 Parameters ranges for sensitivity analysis.

\begin{tabular}{ll}
\hline Parameter & Range \\
\hline Chèzy coefficient $\left[\mathrm{m} / \mathrm{s}^{2}\right]$ & $100-1,000$ \\
Angle of basal friction $[\mathrm{deg}]$ & $10-40$ \\
Angle of internal friction $[\mathrm{deg}]$ & $0-40$ \\
Fluid rate $[\mathrm{m} / \mathrm{s}]$ & $1-20$ \\
\hline
\end{tabular}


Table 2 Ranges and variation steps of parameters values for the two calibration phases.

\begin{tabular}{lllllll}
\hline & \multicolumn{2}{l}{ Coarse calibration } & & \multicolumn{2}{l}{ Fine calibration } \\
\cline { 2 - 3 } \cline { 5 - 6 } Parameter & Range & Variation & & Range & \multicolumn{2}{c}{ Variation } \\
\hline Chèzy coefficient $\left[\mathrm{m} / \mathrm{s}^{2}\right]$ & $100-1,000$ & 100 & & $100-500$ & 50 \\
Angle of basal friction $[\mathrm{deg}]$ & $10-40$ & 5 & & $22.5-27.5$ & 0.5 \\
Angle of internal friction $[\mathrm{deg}]$ & $0-40$ & 5 & & $5-14$ & 1 \\
\hline
\end{tabular}


Table 3 Optimal set of parameters after the calibration.

\begin{tabular}{lll}
\hline Parameter & Set 1 & Set 2 \\
\hline Chèzy coefficient $\left[\mathrm{m} / \mathrm{s}^{2}\right]$ & 250 & 300 \\
Angle of basal friction $[\mathrm{deg}]$ & 24.5 & 25.5 \\
Angle of internal friction $[\mathrm{deg}]$ & 10 & 13 \\
\hline
\end{tabular}




\section{Figures}

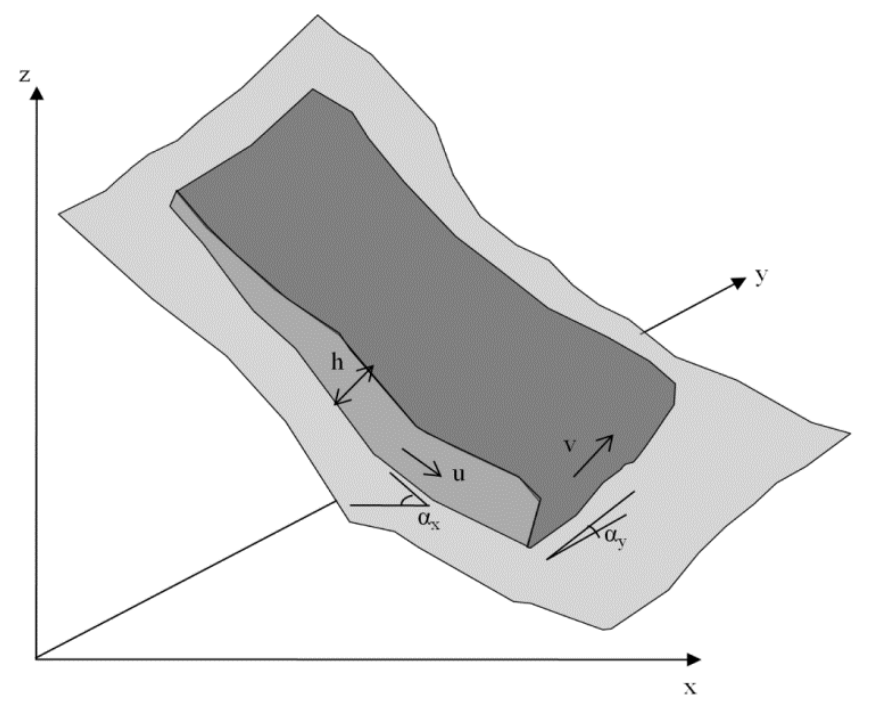

Figure 1 Reference system in MassMov2D model (after Begueria et al. 2009a). 

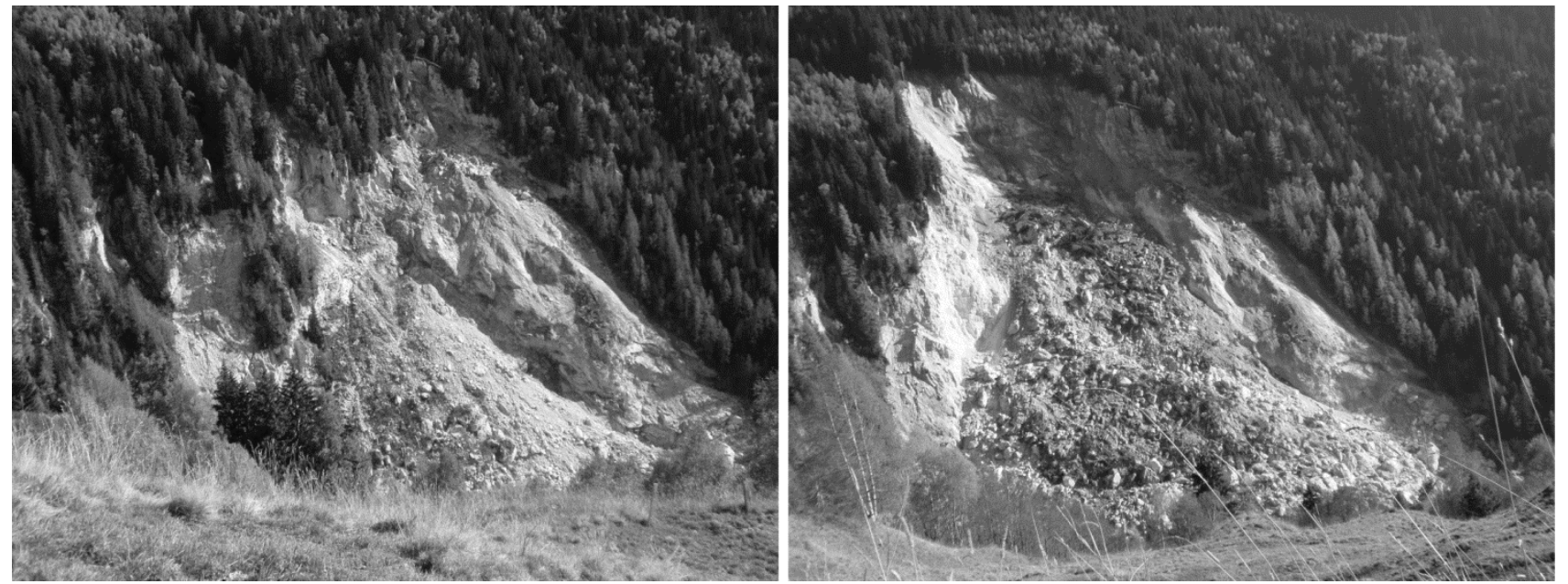

Figure 2 Cè rockfall: before and after the 2009 event. 


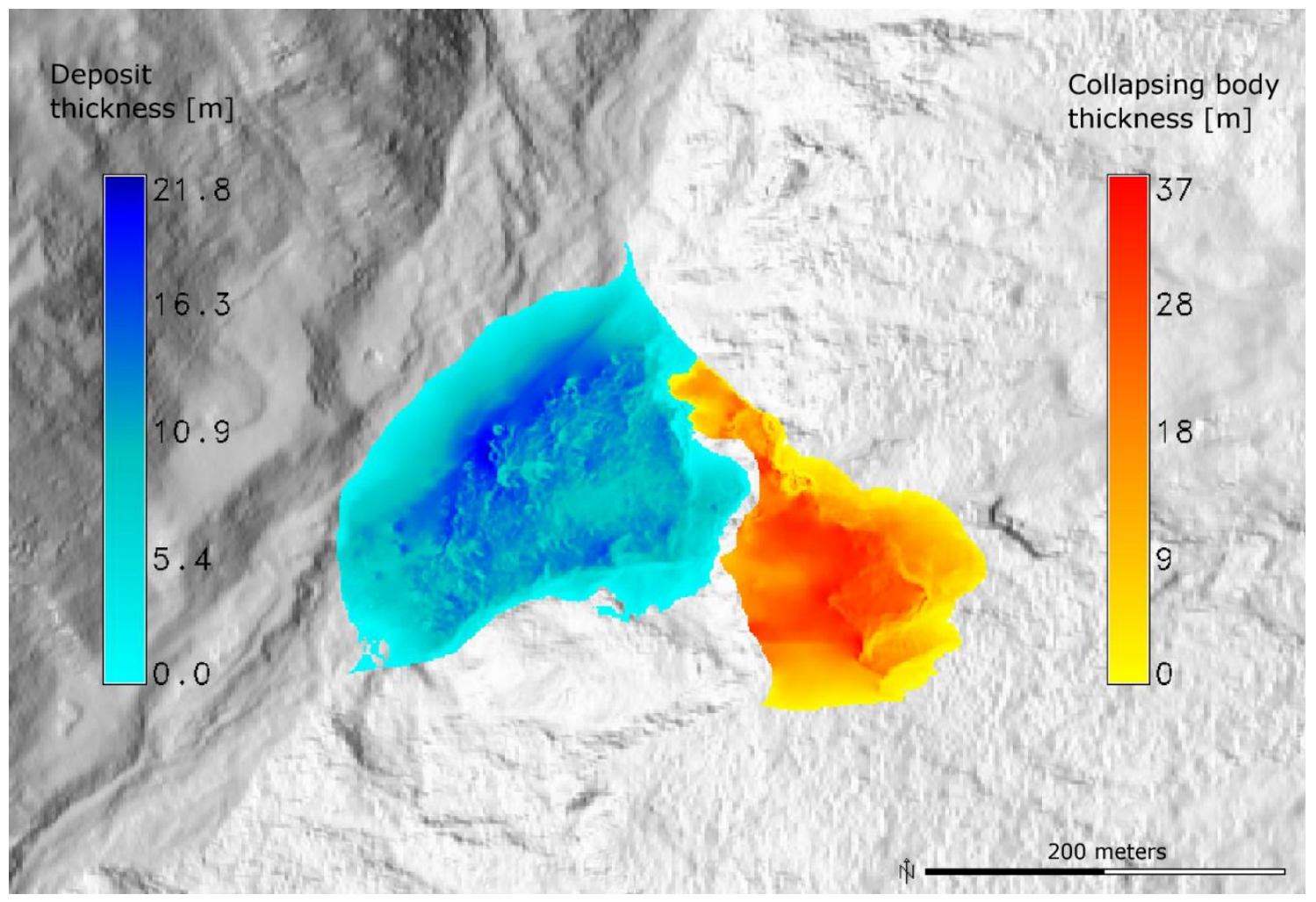

Figure 3 Deposit (in blue) and collapsing body thickness (in red). 


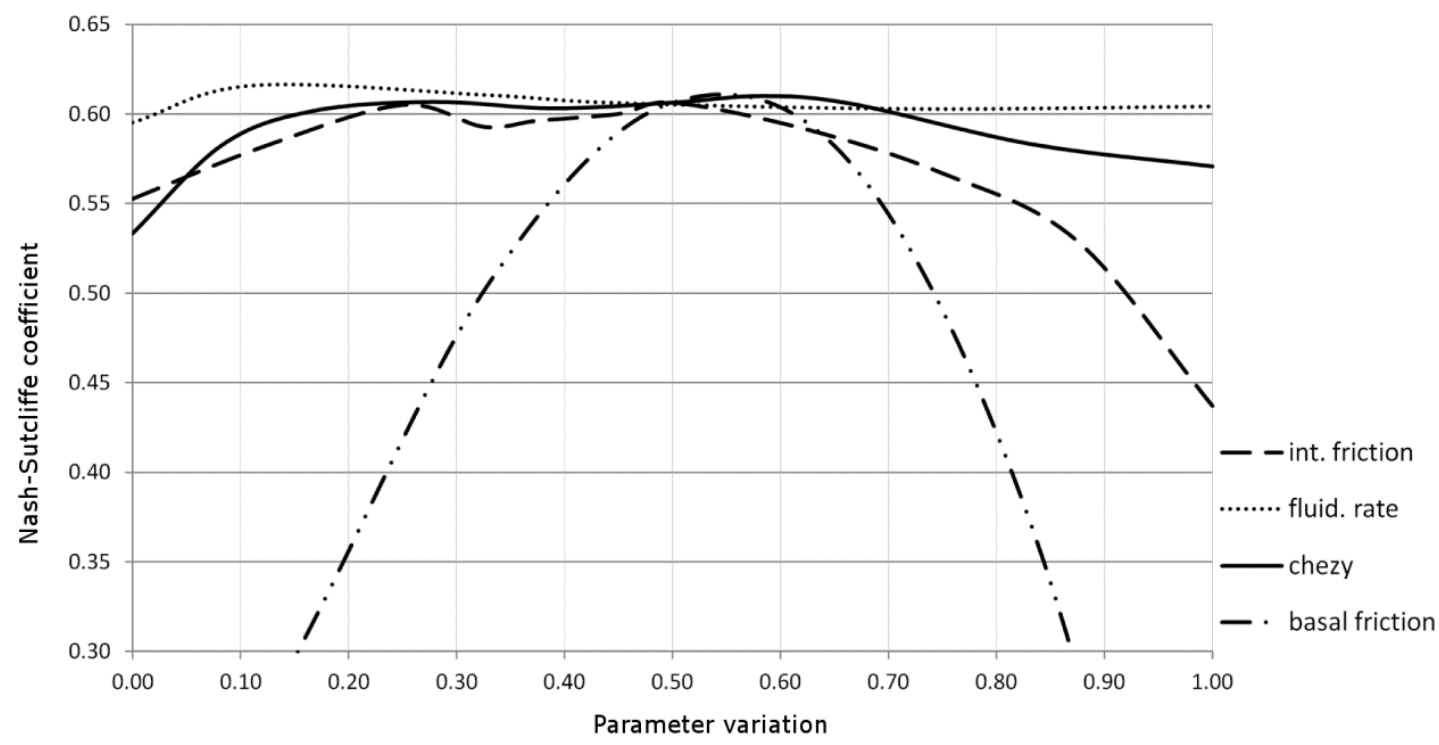

Figure 4 Sensitivity analysis results. 


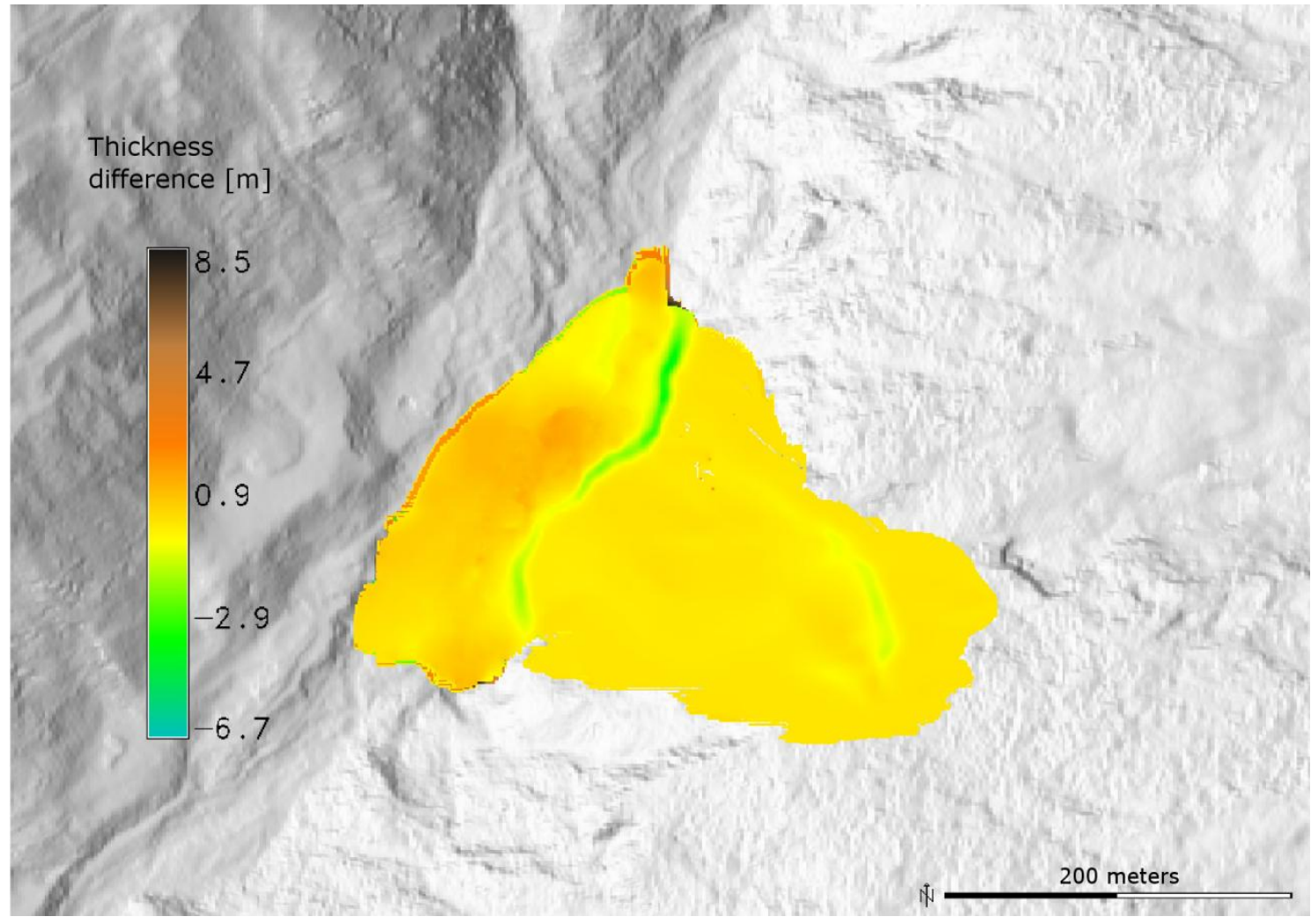

Figure 5 Difference map between simulation 1 and simulation 2. 


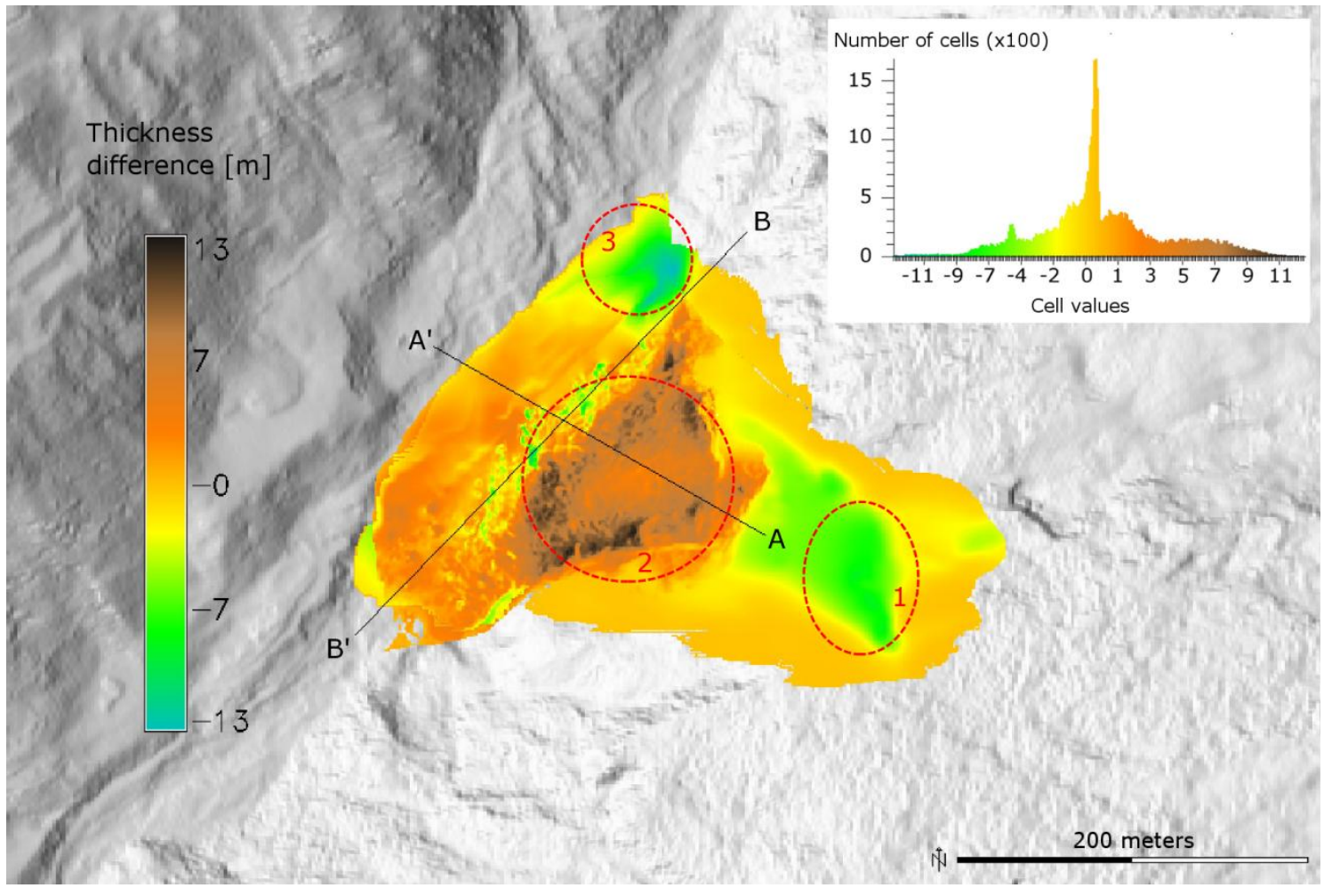

Figure 6 Difference map between observed and modeled deposit and histogram of the cell values. 


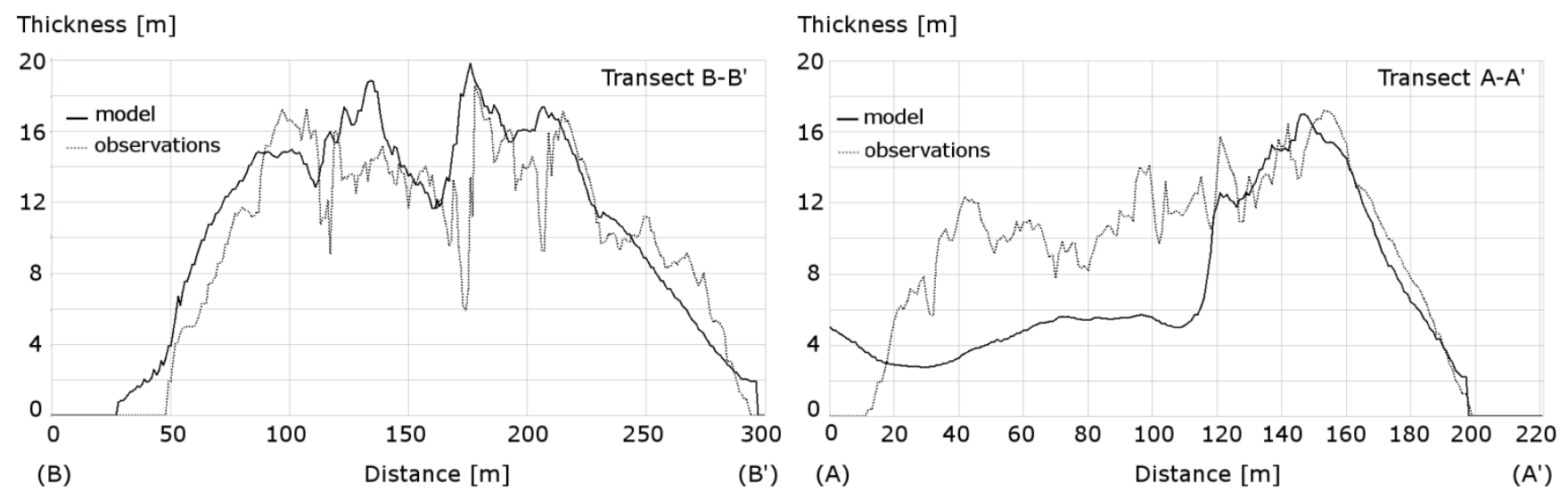

Figure 7 Profiles of the modeled and observed deposit as illustrated in Figure 6. 


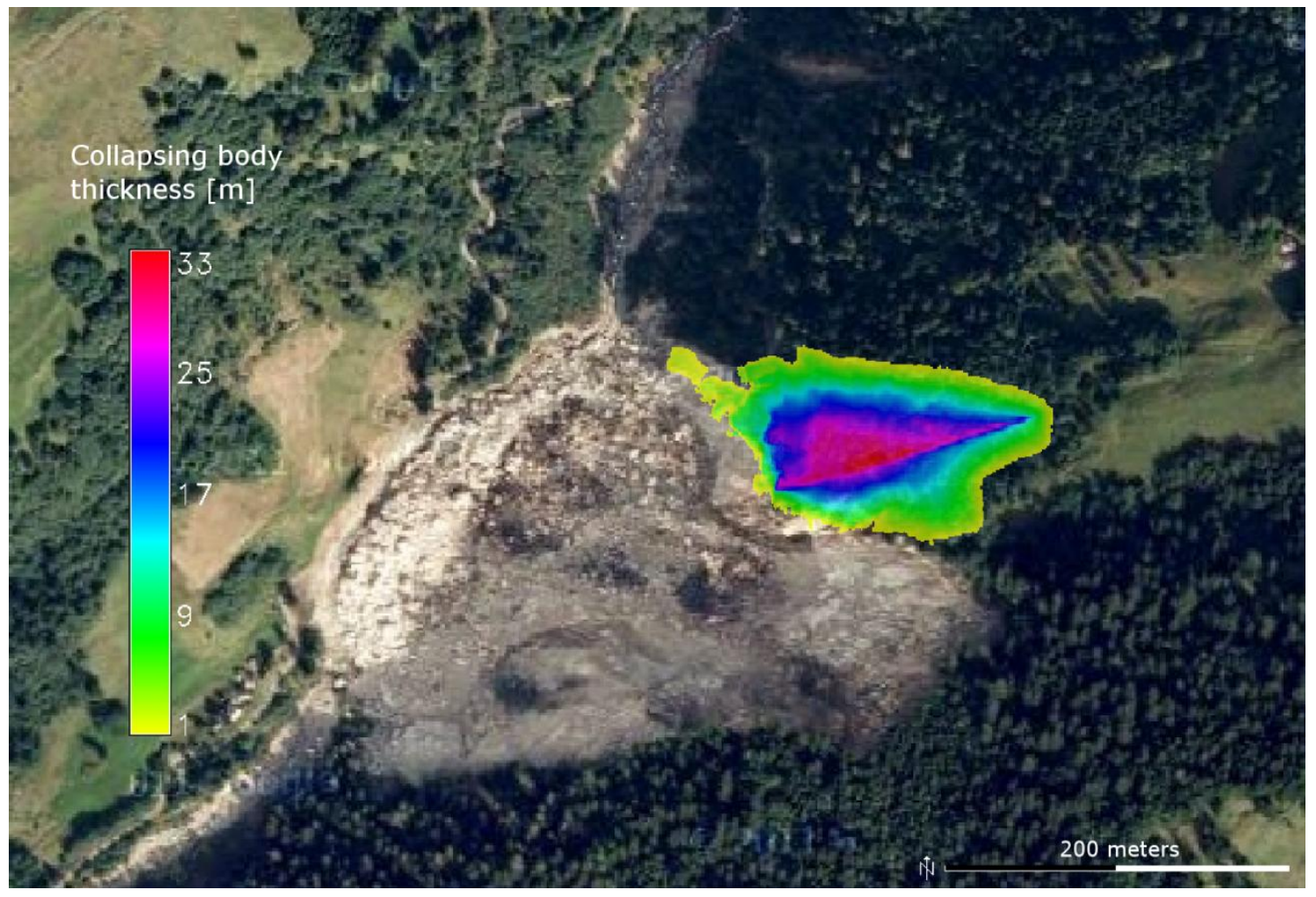

Figure 8 Collapsing body thickness for the hypothesized future scenario. Image source: Google Earth, viewed 20 June 2011. 


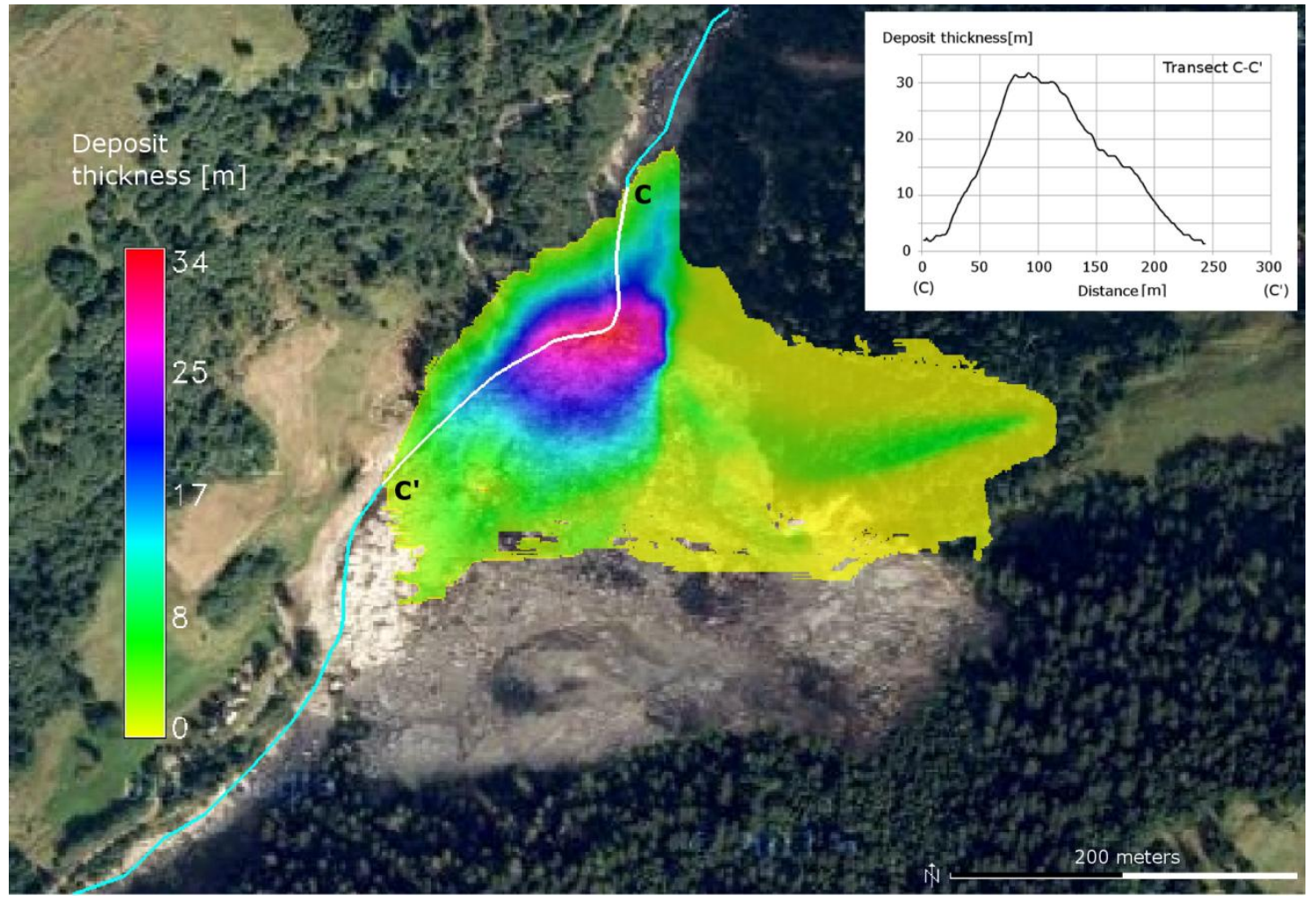

Figure 9 Simulated deposit thickness for the hypothesized future scenario and profile of deposits on the river. Image source: Google Earth, viewed 20 June 2011. 
Figure 1 Reference system in MassMov2D model (after Begueria et al., 2009a).

Figure 2 Cè rockfall: before and after the 2009 event.

Figure 3 Deposit (in blue) and collapsing body thickness (in red).

Figure 4 Sensitivity analysis results.

Figure 5 Difference map between simulation 1 and simulation 2.

Figure 6 Difference map between observed and modeled deposit and histogram of the cell values.

Figure 7 Profiles of the modeled and observed deposit as illustrated in Figure 6.

Figure 8 Collapsing body thickness for the hypothesized future scenario. Image source: Google Earth, viewed 20 June 2011.

Figure 9 Simulated deposit thickness for the hypothesized future scenario and profile of deposits on the river. Image source: Google Earth, viewed 20 June 2011. 